https://dx.doi.org/10.4314/ijs.v21i2.10

Ife Journal of Science vol. 21, no. 2 (2019)

\title{
ANTIMULLERIAN HORMONE SERUM LEVELS: ASSESSING FERTILITY POTENTIAL OF NIGERIAN FEMALES
}

\author{
${ }^{1}$ Azenabor, A., ${ }^{2}$ Bamiro, S.B., ${ }^{1}$ Alo, A.M., ${ }^{1}$ Ekun, O. A., and ${ }^{3}$ Ozurouke, D.F.N. \\ ${ }^{1}$ Department of Medical Laboratory Science, College of Medicine, University of Lagos \\ ${ }^{2}$ Department of Obstetrics and Gynaecology, College of Medicine, University of Lagos. \\ 3Department of Medical Laboratory Science, Achievers University, Owo, Ondo State \\ ${ }^{1}$ Corresponding Author's e-mail: alfredaze@yahoo.com \\ (Received: 24 $4^{\text {th }}$ April, 2018; Accepted: $21^{\text {st }}$ November, 2018)
}

\section{ABSTRACT}

\begin{abstract}
Antimullerian hormone $(\mathrm{AMH})$ is one of the markers used to assess ovarian reserve. While this has been reported to be dependent on genetic and environmental factors, the treatment approach based on AMH level is individualized. This study was designed to compare the efficacy of antimullerian hormone with other markers of ovarian reserve. A longitudinal analytical study was carried out on one hundred and forty-two (142) females comprising hyperprolactinaemic (34), hypergonadotrohic hypogonadism (18), primary hypogonadism (18), polycystic ovarian syndrome (PCOS) (8), diminished ovarian reserve (18), and 46 normal hormonal profile volunteers based on diagnostic criteria. Blood samples were collected from the participants on day 3 for follicle stimulating hormone, luteinizing hormone, estradiol, and antimullerian hormone estimation, and day 21 of the menstrual cycle for prolactin and progesterone. Enzyme linked immuno-sorbent assay technique was used to determine the hormonal levels of the participants. Antimullerian hormone level was higher $(\mathrm{p}<0.05)$ in PCOS when compared with volunteers with normal hormonal profile while no significant differences in antimullerian hormone was observed in all infertile groups $(p>005)$. An inverse association $(p<0.05)$ between antimullerian hormone and estradiol, antimullerian hormone and age as well as estradiol and age were observed in this study. There were no significant correlations between antimullerian hormone and luteinizing hormone as well as between antimullerian hormone and follicle stimulating hormone. In conclusion, antimullerian hormone level was found to be significantly associated with polycystic ovarian syndrome. This also proved to be a marker of age-related ovarian reserve.
\end{abstract}

Keywords: Infertility, Ovarian reserve, Antimullerian Hormone, Follicle stimulating hormone, Estradiol

\section{INTRODUCTION}

Infertility remains a common medical problem globally, with female factors contributing almost equally to male factors (Romero, 2017, Makrigiannakis et al., 2011). In recent years, assessment of ovarian reserve to determine the strategy for treatment of female infertility has become essential. Traditionally; age (Faddy et al., 1992) follicle stimulating hormone (FSH), estradiol (E2) (WHO, 1991), antral follicle count (AFC) (Verhagen et al., 2008) and until recently, antimullerian hormone (AMH) (Jirge, 2011) have been used for evaluation of ovarian reserve. Antimullerian hormone (AMH), belongs to the transforming growth factor $-\beta$ family (VanDisseldrop et al., 2008). In the ovary, it inhibits initial primordial follicle recruitment and decreases the sensitivity of pre-antral and small antral follicles to FSH (La Marca et al., 2007). Basic research data obtained from adult ovary indicate that $\mathrm{AMH}$ is likely to be involved in the regulation of follicular steroidogenesis (Fanchini, 2003) and experiments conducted in animals suggest that AMH reduces aromatase activity and the number of leutinizing hormone (LH) receptors in FSH-stimulated granulosa cells (Josso et al., 1998), and also influences testosterone production by theca cells (Ingraham et al., 2000).

The prediction of poor outcomes during ovarian stimulation is vital for the counseling and management of infertile women in clinical practice (Nelson et al., 2007) on the basis of reduced levels of AMH (Fleming et al., 2013). It is instructive to note from a previous study that AMH values have effectively predicted women at risk of menopause (Sangeeta et al., 2015). While the success of assisted reproductive technology in infertile women depends on the levels of $\mathrm{AMH}$, the individualization in the treatment approach based on AMH levels does not rely on generalized reference values. It is also well documented that 
antimullerian hormone is strongly involved in the pathobiology of polycystic ovarian syndrome (PCOS) (Laven et al.,2004; Pigny et al., 2006) where the increase in serum AMH reflected the increased number of small antral follicles. Clinical evidence reported by Seifer et al., (2007) showed that $\mathrm{AMH}$ is a valuable parameter in the monitoring of follicular exhaustion due to ovarian aging. A previous study conducted elsewhere by Riggs et al., (2008) reported a negative correlation between AMH and FSH; it is not fully established if serum AMH measurements reflect ovarian follicular status better than the conventional hormonal parameters, notably follicle stimulating hormone in our locale. Accumulating evidence suggests that fertility potential and function may be different across racial and ethnic groups and such racial differences have been demonstrated in pubertal timing, infertility, outcomes after assisted reproductive technology treatment and reproductive ageing (Dewailly et al., 2014). The existence of such genetic differences in ovarian reserve and thus fertility potential may have important clinical implications. However, the mechanisms that underlie such are not clear. The aim of this report was to determine the plasma levels of antimuullerian hormones in Nigerian females with different reproductive pathologies. Another objective was to evaluate the fertility potential of the participants, via AMH levels.

\section{MATERIALS AND METHODS}

This study was conducted among 142 females attending the infertility clinic of the Obstetrics and Gynaecology Department of the Lagos University Teaching Hospital (LUTH) Idi- Araba, Lagos; a tertiary health care institution. Ethical approval was obtained from the Health Research and Ethics Committee, College of Medicine of University of Lagos (CMUL/HREC $/ 09 / 17 / 249)$ prior to the commencement of the study. Informed written consent was sought from each of the participants and a well-structured questionnaire was used to obtain information on bio - data of their reproductive histories. The inclusion criteria for the participants were women with a normal menstrual cycle ranging from 26-32 days, women who have not taken any contraceptive pills in the past one year and women between the ages of 18- 46 years. Those excluded include pregnant women and menopausal women, obese individuals, alcoholics, women who have had oophorectomy, tobacco smokers, and those aged 46 and above and below 17 years of age.

\section{Sample Collection}

$5 \mathrm{ml}$ of venous blood was collected from each participant into a plain bottle by venipuncture through the ante - cubital vein. Samples were collected from the participants (on day 3 for FSH, $\mathrm{LH}$, prolactin, estradiol, and $\mathrm{AMH}$ estimation) and (day 21 for progesterone). The collected samples were centrifuged and the sera separated in an Eppendorf tube and kept frozen at $-20^{\circ} \mathrm{C}$ till use.

\section{Biochemical Analyses}

Enzyme-linked immunosorbent assay (ELISA) technique was used for the estimations of $\mathrm{AMH}$, $\mathrm{LH}, \mathrm{FSH}$, prolactin, progesterone and estradiol levels in the participants. The principle was based on the assay system utilizing a high affinity specific monoclonal antibody directed against a distinct antigenic determinant. The antigen was sandwiched between the solid phase and enzyme linked antibodies after a simultaneous reaction. After incubation, and subsequent washing to remove unbound labeled antibody/antigen, reaction with TMB-substrate produced a blue color that changes to a yellow color after the addition of a stop solution. The intensity of color is directly proportional to the amount of hormone in the sample and the intensity was measured at $450 \mathrm{~nm}$ wavelength. The absorbance for each calibrator was plotted against their corresponding concentration and the concentrations of the hormones determined by extrapolation from the curve.

\section{Working Diagnosis}

The participants were classified into different pathologies based on their hormonal profile results as follows:

Hypergonadotropic hypogonadism: Participants with $\mathrm{LH}$, and FSH levels above $10 \mathrm{iu} / \mathrm{L}$ and 12 $\mathrm{iu} / \mathrm{L}$ respectively accompanied with low progesterone levels less than $18 \mathrm{nmol} / \mathrm{L}$.

Hyperprolactinaemia: Participants with prolactin levels above $550 \mathrm{miu} / \mathrm{L}$ despite normal levels of LH, FSH, estradiol and progesterone (Roberts et al., 2008). 
Polycystic Ovarian Syndrome: Participants with $\mathrm{LH} / \mathrm{FSH}$ ratio greater than 2.5 were classified as having polycystic ovarian syndrome and primary hypogonadism include participants with progesterone levels of less than $18 \mathrm{nmol} / \mathrm{L}$ despite normal levels of $\mathrm{LH}, \mathrm{FSH}$, and prolactin (Chun, 2014).

Low Ovarian Reserve: Participants with FSH/LH ratio greater than 2.0 were classified as having low ovarian reserve (Toner and Seifer, 2013).

\section{Statistical Analysis of Data}

The results generated from this study were subjected to statistical analysis using SPSS version 17. Quantitative data were expressed as mean \pm SD. The difference between two means was assessed by student's t-test. Within group and between group analyses was done using one-way analysis of variance (ANOVA). Categorical variables were assessed by Chi square. Pearson's correlation coefficient was used to establish associations between groups.

\section{RESULTS AND DISCUSSION}

The pattern of reproductive pathologies in our participants was such that the proportions documented with hypergonadotrophic hypogonadism, hyperprolactinaemia, polysctic ovarian syndrome, primary hypogonadism and low ovarian reserve were $12.7 \%, 23.9 \%, 5.6 \%$, $12.7 \%$ and $12.7 \%$ respectively (see Table 1 ). The prevalence of PCOS in this study is fairly low compared with what was earlier reported for Caucasians (Asuncion et al., 2013) where a prevalence rate of $6.5-6.7 \%$ was documented. This could be attributed to the non- homogenous nature of our study population, which was entirely made up of participants with both normal and impaired hormonal status. The mean levels of antimullerian hormone in PCOS (48.29 \pm 20.15 $\mathrm{Au} / \mathrm{ml}$ ) was significantly higher than the levels in participants with normal reproductive hormone profile $(32.97 \pm 5.11 \mathrm{Au} / \mathrm{ml}, \mathrm{p}=0.050)$. These and other results are shown in table 2. Tables 3 and 4 show correlation studies of AMH with other reproductive hormones in various reproductive pathologies and age respectively. Table 5 depicts the levels (mean $\pm \mathrm{SD}$ ) of $\mathrm{AMH}$ in different age groups of the participants with different pathologies and subjects with normal reproductive hormonal profile. The Interrelationship between antimullerian hormone and reproductive hormones is illustrated in table 6.

Table 1: The Frequency of Reproductive Pathologies in the Study Population of Infertile Females

\begin{tabular}{lcr}
\hline Reproductive Pathologies & Frequency (n) & Per \\
\hline & & \\
Hypergonadotrophic hypogonadism & 18 & 12.7 \\
Hyperprolactinaemia & 34 & 23.9 \\
Primary hypogonadism & 18 & 12.7 \\
Polycystic ovarian syndrome & 8 & 5.6 \\
Diminished ovarian syndrome & 18 & 12.7 \\
Normal hormonal profile & 46 & 32.4 \\
Total number of subjects & 142 & 100
\end{tabular}


Table 2: Serum Levels (Mean \pm SEM) of Antimullerian Hormones in Infertile Female Subjects with Reproductive Pathologies in Comparison with Normal Hormonal Profile Subjects

Reproductive Pathologies

Polycystic ovarian syndrome

Normal hormonal profile

Hyperprolactinaemia

Normal hormonal profile

Hypergonadotrophic hypogonadism

Normal hormonal profile

Primary hypogonadism

Normal

Diminished Ovarian reserve

Normal
Antimullerian Hormone

$\mathrm{p}$ values

$48.29 \pm 20.15$

$32.97 \pm 5.11$

$32.85 \pm 4.78$

0.987

$32.97 \pm 5.11$

$19.44 \pm 6.66$

0.151

$32.97 \pm 5.11$

$20.64 \pm 6.59$

0.189

$32.97 \pm 5.11$

$35.77 \pm 7.33$

0.767

$0.050^{*}$

$32.98 \pm 5.11$

* significance. Serum levels of Antimullerian Hormones in subjects with polyscystic ovarian syndrome were significantly higher when compared with subjects with normal reproductive hormone levels. 
Table 3: Pearson Correlation Coefficient of AMH with Other Reproductive Hormones in Various Reproductive Pathologies

\begin{tabular}{|c|c|c|}
\hline Infertile Subjects & Reproductive Hormones & $\begin{array}{l}\text { AMH } \\
\text { r (p) }\end{array}$ \\
\hline \multirow[t]{5}{*}{ Polycystic ovarian syndrome } & $\mathrm{LH}$ & $-0.206(0.794)$ \\
\hline & $\mathrm{FSH}$ & $0.159(0.841)$ \\
\hline & PROL & $-0.010(0.990)$ \\
\hline & PROG & $0.457(0.543)$ \\
\hline & E2 & $-0133(0.867)$ \\
\hline \multirow[t]{5}{*}{ Hyperprolactinaemia } & LH & $0.099(0.707)$ \\
\hline & FSH & $0.074(0.778)$ \\
\hline & PROL & $0.087(0.741)$ \\
\hline & PROG & $-0 .-067(0.797)$ \\
\hline & E2 & $-0.304(0.236)$ \\
\hline \multirow[t]{5}{*}{ Hypergonadotrophic hypogonadism } & $\mathrm{LH}$ & $0.057(0.884)$ \\
\hline & FSH & $0.158(0.684)$ \\
\hline & PROL & $0.164(0.674)$ \\
\hline & PROG & $-0.105(0.788)$ \\
\hline & E2 & $-0.408(0.276)$ \\
\hline \multirow[t]{5}{*}{ Primary hypogonadism } & LH & $-0.023(0.953)$ \\
\hline & FSH & $0.102(0.793)$ \\
\hline & PROL & $0.151(0.699)$ \\
\hline & PROG & $-0.116(0.767)$ \\
\hline & E2 & $-0.493(0.178)$ \\
\hline \multirow[t]{5}{*}{ Diminished ovarian reserve } & LH & $0.316(0.407)$ \\
\hline & FSH & $0.495(0.175)$ \\
\hline & PROL & $0.267(0.487)$ \\
\hline & PROG & $0.365(0.334)$ \\
\hline & $\mathrm{E} 2$ & $-0.275(0.474)$ \\
\hline \multirow[t]{5}{*}{ Normal } & LH & $0.252(0.245)$ \\
\hline & FSH & $0.122(0.580)$ \\
\hline & PROL & $0.113(0.607)$ \\
\hline & PROG & $-0.153(0.486)$ \\
\hline & E2 & $-0.260(0.231)$ \\
\hline
\end{tabular}

Table 4: Correlation Studies of Age and Reproductive Hormones

\begin{tabular}{ll}
\hline Reproductive Hormones & Age $\mathbf{r}(\mathbf{p})$ \\
\hline Antimullerian hormone & $-0.237(0.049)^{*}$ \\
FSH & $0.030(0.806)$ \\
LH & $0.205(0.094)$ \\
E2 & $-0.382(0.001)^{*}$ \\
\hline
\end{tabular}

*significant. Antimullerian hormone showed a significant inverse correlation with age. 
Table 5: Serum Levels (Mean \pm SD) of Antimullerian Hormone in Infertile Subjects with Different Reproductive Pathologies and Normal Hormonal Profile Subjects

\begin{tabular}{lcc}
\hline Reproductive Pathologies & Age Group & Antimullerian Hormone (Mean \pm SD) \\
\hline Normal Hormone Profile & $21-30$ & $39.16 \pm 21.43$ \\
& $31-40$ & $30.95 \pm 17.85$ \\
Hyperprolactinaemia & $>40$ & $21.18 \pm 35.65$ \\
& $21-30$ & $34.57 \pm 20.64$ \\
Hypergonadotropic Hypognadism & $31-40$ & $32.69 \pm 20.11$ \\
& $>40$ & $22.14 \pm 8.59$ \\
Polycystic Ovarian Syndrome & $21-30$ & 59.48 \\
& $31-40$ & $14.14 \pm 15.1 .9$ \\
Primary Hypogonadism & $>40$ & 16.49 \\
& $21-30$ & - \\
Diminished Ovarian Reserve & $31-40$ & $28.56 \pm 28.78$ \\
& $>40$ & $46.02 \pm 61.14$ \\
& $21-30$ & $40.98 \pm 26.15$ \\
& $31-40$ & $14.58 \pm 16.59$ \\
& $>40$ & 16.49 \\
& $21-30$ & $45.22 \pm 17.15$ \\
& $31-40$ & $31.01 \pm 22.92$ \\
\hline
\end{tabular}

Table 6: Interrelationship between AMH and Reproductive Hormones

\begin{tabular}{cc}
\hline Reproductive hormones & $\mathbf{r}(\mathbf{p})$ \\
\hline FSH & $-0.089(0.458)$ \\
LH & $-0.112(0.354)$ \\
E2 & $-0.307(0.009) *$ \\
\hline
\end{tabular}

*significance. Antimullerian hormone showed a significant inverse correlation with estradiol (E2)

This study revealed a significantly higher antimullerian hormone levels in PCOS when compared with subjects with normal hormonal profile. This is in agreement what other reported studies elsewhere (Bungum et al., 2013; Neoklis, et al., 2013). In conditions with high LH and normal or low FSH as in PCOS, AMH concentrations in this study showed no correlation with FSH and this observation is in tandem with the study of Neoklis et al., (2013). By implication, increased levels of AMH in PCOS are thus a reflection of growing follicles (Velvekar et al., 2016). A link with follicular growth implies the strength of $\mathrm{AMH}$ as a marker of severity of ovarian dysfunction and hyperandrogenism in women with anovulatory PCOS. However, AMH may not be a useful guide in the exact characterization of reproductive pathologies. This is evident from the Pearson correlation coefficient studies conducted between reproductive hormones and $\mathrm{AMH}$ in different reproductive pathologies. We have also shown in this study that both endocrine (FSH, LH and E2) and clinical marker (age) of ovarian reserve independently correlated with plasma $\mathrm{AMH}$ values, where an inverse association of AMH with age $(r=-0.237, p=0.049)$ and $E 2(r=-$ $0.382, p=0.001)$ were observed. The level of $\mathrm{AMH}$ thus serves as a useful marker of age dependent fall in the follicular potential of the ovary of the study participants. This observation was corroborated in our participants with normal reproductive hormone profile, where a gradual decrease in $\mathrm{AMH}$ was observed with aging and as well in those with hyperprolactinaemia. This underscores the importance of age as an important factor in determining quality and quantity of ovarian reserve. Interestingly, FSH did not show any association with age in our study participants. This is at variance with a positive correlation earlier reported by Velvekar et al, (2016). The reliability of FSH alone in assessing ovarian reserve in our study population is limited, in view of the lack of correlation with age observed. This is against the backdrop of the 
World Health Organization classification of ovarian dysfunction which was hitherto based on serum FSH and estradiol levels. Consequently, the interpretation and use of follicle stimulating hormone should be done with caution. This may be due to the fact that FSH exhibits both inter and intra cyclic fluctuations, thus single day 3 FSH measurement may fail to be an accurate marker, suggesting evaluation of subsequent cycle's day 3 FSH (Perloe, et al., 2000). Further examination of the interrelationship of $\mathrm{AMH}$ with other reproductive hormones showed a negative correlation with estradiol $(r=-0.307, p=0.009)$, while no significant correlations were observed with $\mathrm{LH}$ and FSH. The data on FSH is in agreement with a previous study (Omabe et al., 2013). The reported correlation between AMH and $\mathrm{E} 2$ could be attributed to the fact that $\mathrm{AMH}$ is not affected by the hypothalamic pituitary axis, oral contraceptives and other ovarian factors.

\section{CONCLUSION}

From the data generated, AMH level could be a useful marker of age-related ovarian reserve in our study participants. However, no significant correlation was observed with other hormones in different reproductive pathologies. This study has provided baseline information on the usefulness of $\mathrm{AMH}$ in assessing fertility potential of Nigerian females and calls for further studies in this field.

Acknowledgements: Authors are grateful to $\mathrm{Mr}$ Abayomi Lawal for statistical analysis of data.

Conflict of Interest: None declared.

\section{REFERENCES}

Asuncion, M., Calvo, R.M., San Millan, J.L., Sancho, J, Avilla, S., Escobar-Morreale, H.F. 2000 A porspective study of the prevalence of the polycystic ovary syndrome in unselected Caucasian women from spain. Journal of Clinical Endcrinology and Metabolism, 85:2434-2438.

Bungum, L., Franssohn, F., Bungum, M., Humaidan, P., Giwercman, A. 2013. The circadian variation in Anti-Müllerian hormone in patients with polycystic ovary syndrome differs significantly from normally ovulating women. PLoS ONE, 8 (9).

Chun, S. 2014 Serum luteinizing hormone level and luteinizing hormone/follicle stimulating hormone ratio but not serum anti-Müllerian hormone level is related to ovarian volume in Korean women with polycystic ovary syndrome. Clinical and Experimental Reproductive Medicine, 41 (2): 86-91.

Dewailly, D., Andersen, C.Y., Balen, A. 2014. The physiology and clinical utility of antiMüllerian hormone in women. Human Reproduction Update, 20 (3):370-385.

Faddy, M.J., Gosden, R.G., Gougeon, A., Richardson, S.J., Nelson, J.F. 1992. Accelerated disappearance of ovarian follicles in mid-life: implications for forecasting menopause. Human Reproduction, 7(10):1342-1346.

Fanchin, R., Schonäuer, L.M., Righini, C., Guibourdenche, J., Frydman, R., Taieb, J. 2003. Serum anti-Müllerian hormone is more strongly related to ovarian follicular status than serum inhibin B, estradiol, FSH and LH on day 3. Human Reproduction, 18 (2):323-327.

Fleming, R., Broekmans, F., Calhaz-Jorge, C. 2013. Can anti-Müllerian hormone concentrations be used to determine gonadotrophin dose and treatment protocol for ovarian stimulation? Reproductive BioMedicine Online, 26 (5):431-439.

Ingraham, H.A., Hirokawa, Y., Roberts, L.M., Mellon, S.H., McGee, E., Nachtigal, M.W., Visser, J.A.. 2000. Autocrine and paracrine Müllerian inhibiting substance hormone signaling in reproduction. Recent Progress in Hormone Research. 55:53-67.

Josso, N, Racine, C, Di Clemente, N, Rodolfo, Rey, RR, Xavier, F. 1998. The role of antiMüllerian hormone in gonadal development. Molecular and Cellular Endocrinology,145 (1-2):3-7.

Jirge, P.R. 2011. Ovarian reserve tests. J Hum Reprod Sci., 4(3):108-113.

Laven, J.S., Mulders, A.G., Visser, J.A., Themmen, A.P., De Jong, F.H., Fauser, B.C. 2004. Anti-Müllerian hormone serum 
concentrations in normoovulatory and anovulatory women of reproductive age. $J$ Clin Endocrinol Metab, (89):318-323.

La Marca, A., Giulini, S., Tirelli, A., Bertucci, E., Marsella, T., Xella, S., Volpe, A. 2007. AntiMu"llerian hormone measurement on any day of the menstrual cycle strongly predicts ovarian response in assisted reproductive technology. Hum. Reprod., 22:766-771.

Makrigiannakis, A., Petsas, G., Toth, B., Relakis, K., Jeschke, U. 2011. Recent advance in understanding immunology of reproductive failure. I Reprod Immunol, 90: 96-104.

Nelson, S.M., Yates, R.W., Fleming, R. 2007. Serum anti-Mullerian hormone and FSH: prediction of live birth and extremes of response in stimulated cycles implications for individualization of therapy. Hum. Reprod, 22: 2414-2421.

Neoklis, A.G., Eleni, K., Vasiliki, K., Nikolaos, D.R., Anastasia, A., Dimitra, M., Efstathios, P., Dimitrios, P. 2013. Frequency of the Anti-Müllerian-Inhibiting Hormone Receptor 2 (AMHR2) 482 A $>$ G Polymorphism in Women With Polycystic Ovary Syndrome: Relationship to Luteinizing Hormone Levels. J. Clin Endocrinol Metab, 98 (11): 1866 - 1870.

Omabe, M, Ezeani, M., Okwuegbu, M. 2013. Clinical Utilities of Anti Mullerian Hormones. Sch.J.App.Med.Sci, 1 (5): $606-$ 618.

Perloe, M., Levy, DP., Sills, ES. 2000. Strategies for ascertaining ovarian reserve among women suspected of subfertility. International Journal of Fertility and Women's Medicine, 45(3): 215-224.

Pigny, P. Jonard, S. Robert, Y. Dewailly, D. 2006. Serum anti-Müllerian hormone as a surrogate for antral follicle count for definition of the polycystic ovary syndrome. J Clin Endocrinol Metab., (91): 941-945.

Riggs, R.M., Duran, E.H., Baker, M.W., Dimble, T.D., Hobeika, E., Yin, L. 2008. Assessment of ovarian reserve with anti-mullerian hormone: a comparison of predictive value of anti-Mullerian hormone, follicle -stimulating hormone, inhibin, and age.
Am.J. Obstet. Gynecol., 199:202-208.

Roberts, W.L., McMillin, G.A., Burtis, C.A., Bruns, D.E. 2008 Reference Information for the Clinical Laboratory Blood gases. In Tietz Fundamentals of Clinical Chemistry, 836873.

Romero, R. 2007. Prevention of spontaneous preterm birth: the role of sonographic cervical length in identifying patients who may benefit from progressive treatment. Ultrasound Obstet Gynaecol., 30: 675 686.

Sangeeta, N, James, C.S., James, G.T., Duke, A., Imo, E., Erica, W., David, S., Barbara, S., Pamela, J., Cora, E.L., Edmond, K.K., and Melissa, F.W. 2015.Anti-Mullerian Hormone (AMH) is Associated with Natural Menopause in a Population-Based Sample: The Cardia Women's Study. Maturitas, 81 (4): 493 - 496.

Seifer, D.B., MacLaughlin, D.T. 2007. Mullerian Inhibiting Substance is an ovarian growth factor of emerging clinical significance," Fertility and Sterility, 88 (3): 539-546.

Toner, JP., Seifer, DB. 2013: Why we may abandon basal folliclestimulating hormone testing: a sea changes in determining ovarian reserve using antimullerian hormone. Fertil. Steril., 99: 1825-1830.

Van Disseldorp, J., Faddy, M.J., Themmen, A.P., de Jong, F.H., Peeters, P.H., van der Schouw, Y.T. 2008. Relationship of serum antimullerian hormone concentration to age at menopause. J Clin Endocrinol Metab., 93: 2129-34.

Velvekar, U., Lakshmi, S., Kumar, A. 2016. Study of Ovarian Reserve Parameters in Infertile Women of Different Age Groups. Int.J.Reprod Contracept.Obstet Gynaecol., 5 (7): 2116-2121.

Verhagen, T.E., Hendriks, D.J., Bancsi, L.F., Mol, B.W., Broekmans, F.J. 2008. The accuracy of multivariate models predicting ovarian reserve and pregnancy after in vitro fertilization: A meta-analysis. Hum Reprod Update, 14: 95-100.

World Health Organization.,1991. Programme on maternal and child health and family planning. Division of Family Health .World Health Organization: Geneva. 